Article

\title{
Non-Cytotoxic Quantum Dot-Chitosan Nanogel Biosensing Probe for Potential Cancer Targeting Agent
}

\author{
Tyler Maxwell 1,2, Tahmina Banu ${ }^{2,3}$, Edward Price ${ }^{1,2}$, Jeremy Tharkur ${ }^{2,4}$, \\ Maria Gabriela Nogueira Campos ${ }^{2,5}$, Andre Gesquiere ${ }^{1,2,3,6, *}$ and Swadeshmukul Santra ${ }^{1,2,3,4, *}$
}

1 Department of Chemistry, University of Central Florida, 4000 Central Florida Blvd., Orlando, FL 32816, USA; E-Mails: tyler.maxwell@knights.ucf.edu (T.M.); eprice2@knights.ucf.edu (E.P.)

2 NanoScience Technology Center, University of Central Florida, 12424 Research Parkway, Suite 400, Orlando, FL 32826, USA; E-Mails: tahminabanu@knights.ucf.edu (T.B.); jeremyt@knights.ucf.edu (J.T.); maria.nogueiracampos@ucf.edu (M.G.N.C.)

3 Department of Material Science and Engineering, University of Central Florida, 127600 Pegasus Drive, Engineering 1, Suite 207, Orlando, FL 32816, USA

4 Burnett School of Biomedical Sciences, University of Central Florida College of Medicine, 6900 Lake Nona Boulevard, Orlando, FL 32827, USA

5 Institute of Science and Technology, Federal University of Alfenas, Rodovia José Aurélio Vilela, 11999, Poços de Caldas, MG 37715-400, Brazil

6 College of Optics and Photonics, University of Central Florida, P.O. Box 162700, Orlando, FL 32816, USA

* Authors to whom correspondence should be addressed; E-Mails: andre@ucf.edu (A.G.); swadeshmukul.santra@ucf.edu (S.S.); Tel.: +1-407-454-1317 (A.G.); +1-407-882-2848 (S.S.); Fax: +1-407-882-2819 (A.G. \& S.S.).

Academic Editor: Andrea Danani

Received: 16 November 2015 / Accepted: 15 December 2015 / Published: 18 December 2015

Abstract: Quantum dot (Qdot) biosensors have consistently provided valuable information to researchers about cellular activity due to their unique fluorescent properties. Many of the most popularly used Qdots contain cadmium, posing the risk of toxicity that could negate their attractive optical properties. The design of a non-cytotoxic probe usually involves multiple components and a complex synthesis process. In this paper, the design and synthesis of a non-cytotoxic Qdot-chitosan nanogel composite using straight-forward cyanogen bromide $(\mathrm{CNBr})$ coupling is reported. The probe was characterized by spectroscopy (UV-Vis, fluorescence), microscopy (Fluorescence, Scanning Electron Microscopy (SEM), Transmission Electron Microscopy (TEM) and Dynamic Light Scattering. This activatable 
(“OFF"/“ON”) probe contains a core-shell Qdot (CdS:Mn/ZnS) capped with dopamine, which acts as a fluorescence quencher and a model drug. Dopamine capped "OFF" Qdots can undergo ligand exchange with intercellular glutathione, which turns the Qdots "ON" to restore fluorescence. These Qdots were then coated with chitosan (natural biocompatible polymer) functionalized with folic acid (targeting motif) and Fluorescein Isothiocyanate (FITC; fluorescent dye). To demonstrate cancer cell targetability, the interaction of the probe with cells that express different folate receptor levels was analyzed, and the cytotoxicity of the probe was evaluated on these cells and was shown to be nontoxic even at concentrations as high as $100 \mathrm{mg} / \mathrm{L}$.

Keywords: quantum dot; biosensor; chitosan; drug delivery; cancer; nanogel

\section{Introduction}

Quantum dots (Qdots) are small crystals made of semiconductor material that possess unique size dependent optical properties due to confinement of their electronic states [1-4]. Luminescent Qdots are photo-stable compared to traditional organic dies, which has led to their study for in vitro and in vivo imaging [2,5,6]. A core-shell structure is commonly employed in Qdot synthesis to achieve high quantum yield, and to lower the toxic effects of cadmium [1,5,7,8]. Qdots have a broad excitation and tunable emission spectra, which allows for multiplexed imaging [9-11]. Targeted delivery of Qdots to cells for sensing and imaging applications has been refined in recent years by attaching antibodies, proteins, and other small molecules to the Qdot surface for highly sensitive whole body imaging and detection. These nanoparticles have also been employed for multimodal imaging by attachment of magnetic particles for MRI [8,12-14] and optical imaging [15] of tumor cells. Previous studies have shown that Qdots show promise as vehicles for the delivery of drugs as they can be conjugated with multiple functionalities for targeted delivery and imaging of drug release events $[5,6,9]$.

Currently, there has been much research focused on activatable Qdots for drug delivery and imaging $[7,8,16]$. Typically, when loaded with drugs, these Qdots are put in the "OFF" state with their fluorescence quenched due to energy transfer from the Qdot to the drug or a drug-quencher composite. When the quencher is separated from the Qdot fluorescence is restored [17]. This type of probe reports on drug release events in situ by observed changes in fluorescence intensity or wavelength $[8,18]$. Previous studies have shown that dopamine bound to the surface of a Qdot will quench the Qdot fluorescence due to electron transfer from the electron rich dopamine to the hole in the valence band of the excited Qdot core [19-21]. Our previous work has shown that the fluorescence of the dopamine-Qdot conjugate can be restored upon reduction of the disulfide bond by glutathione (GSH) [19]. These activatable Qdots are photo-stable in solution but have limited applications for bioimaging and drug delivery unless functionalized further. These Qdots are then embedded in a polymer network, which helps to minimize Qdot agglomeration and degradation [22,23]. Qdot-polymer composite materials with multiple fluorophores for quantification of relevant molecules at the cellular level are currently being studied [4]. Composite materials are being studied due to their potential applications for topical delivery 
of drugs and for when single nanosized particles are not desired. These sensors, despite their usefulness, are often difficult and time consuming to synthesize and purify.

To address this shortcoming with existing Qdot-polymer composite sensors, we report an activatable Qdot-chitosan composite gel probe (full probe) to be used for cell tracking and drug delivery. This proof-of-concept study employs $\mathrm{Mn}^{2+}$ doped $\mathrm{CdS} / \mathrm{ZnS}$ core shell Qdots capped with dopamine. The Qdots are fabricated at room temperature using a water-in-oil (W/O) micro-emulsion system, and dopamine is used as a capping agent and quencher of the Qdot fluorescence [20,21,24]. This gives the Qdot activatable properties, since the disulfide bond connecting the dopamine quencher to the Qdot particle is easily broken through reduction by intracellular glutathione [7,8]. The dopamine also acts as a model drug, simulating intercellular drug delivery. These Qdots are then crosslinked to hydrothermally treated chitosan to create a piggyback style, nontoxic, multifunctional probe in a one-step process by using $\mathrm{CNBr}$ chemistry. In this cross-linking step, several ligands are also attached to chitosan, including folic acid [5,25-27] (FA, targeting motif), polyethylene glycol (PEG dispersing agent) and fluorescein isothiocyanate (FITC, dye for particle tracking). FITC is bound to the chitosan to track the particles in their "OFF" state. Cytotoxicity and interaction of the probe with cells were studied in vitro for OVCAR3 (human ovarian cancer), TE71 (murine thymus epithelial), RAW264.7 (murine macrophage) and J774a.1 (murine macrophage). OVCAR3 was selected as it has been shown to overexpress folate receptors, making it an easy target for a folate conjugated particles [28,29]. TE71 cells were chosen as they would represent a typical non-cancerous endothelial cell that a nanoparticle would encounter in vivo. J774a.1 monocytes were selected due to both their surface folate receptor expression, and for the preliminary determination of cytotoxic effects of the probe on systemic macrophages encountered in vivo. The multimodal functionality and piggyback structure of this probe will allow it to be used in the future by researchers for targeted drug delivery and cell tracking.

\section{Results and Discussion}

\subsection{Probe Design}

The probe was designed to be a nontoxic chitosan nanogel with an embedded activatable Qdot probe to make a composite biosensing material. Core/shell CdS:Mn/ZnS Qdots were used in this study because the $\mathrm{ZnS}$ shell renders the Qdots brighter and largely non-cytotoxic [30,31]. As shown in Scheme 1, the basic principle behind the activatability of the quantum dots is the quenching of the Qdot due to electron transfer from dopamine bound to the Qdot [19]. The dopamine is first converted to dopamine dithiocarbamate, which has two sulfur atoms able to form disulfide bonds with the ZnS Qdot shell (Dopamine-Qdot) $[19,32,33]$. When these quantum dots enter a cell, they will interact with intracellular glutathione where concentrations can reach $10 \mathrm{mM}$ [34]. Glutathione is able to perform ligand exchange with the dopamine on the Qdot surface [19]. The release of dopamine from the Qdot surface restores the Qdot fluorescence. This activatability was incorporated to allow for activated drug release and reporting on this event upon internalization by the cell. Previous studies have shown that some cancer cells have elevated levels of glutathione, theorized to be a response to increased free radical concentrations [34-36]. This makes glutathione mediated activation a viable route for triggering drug release events. 
Hydrothermally treated chitosan particles were chosen for functionalizing the Qdots because they are biocompatible, soluble in water, and contain a primary amine group that can be exploited for ligand attachment [37-39]. FITC was attached to the chitosan to be used for particle tracking purposes as its fluorescence is always "ON", unlike the Qdot. The chitosan was cross-linked around the Qdots and to the targeting ligand (FA) to form the full probe. The probe was synthesized with folic acid (+) FA and without folic acid (-) FA CNBr chemistry, which binds primary amine groups to alcohol groups, and was used as a cross-linker. $\mathrm{CNBr}$ was chosen to cross-link the components because cross-linking can be completed in one step. In addition, $\mathrm{CNBr}$ reacts with the widely available amine and alcohol groups in chitosan, folic acid, PEG, and dopamine. After cross-linking, the gel probe was washed with ethanol to remove any unbound components.

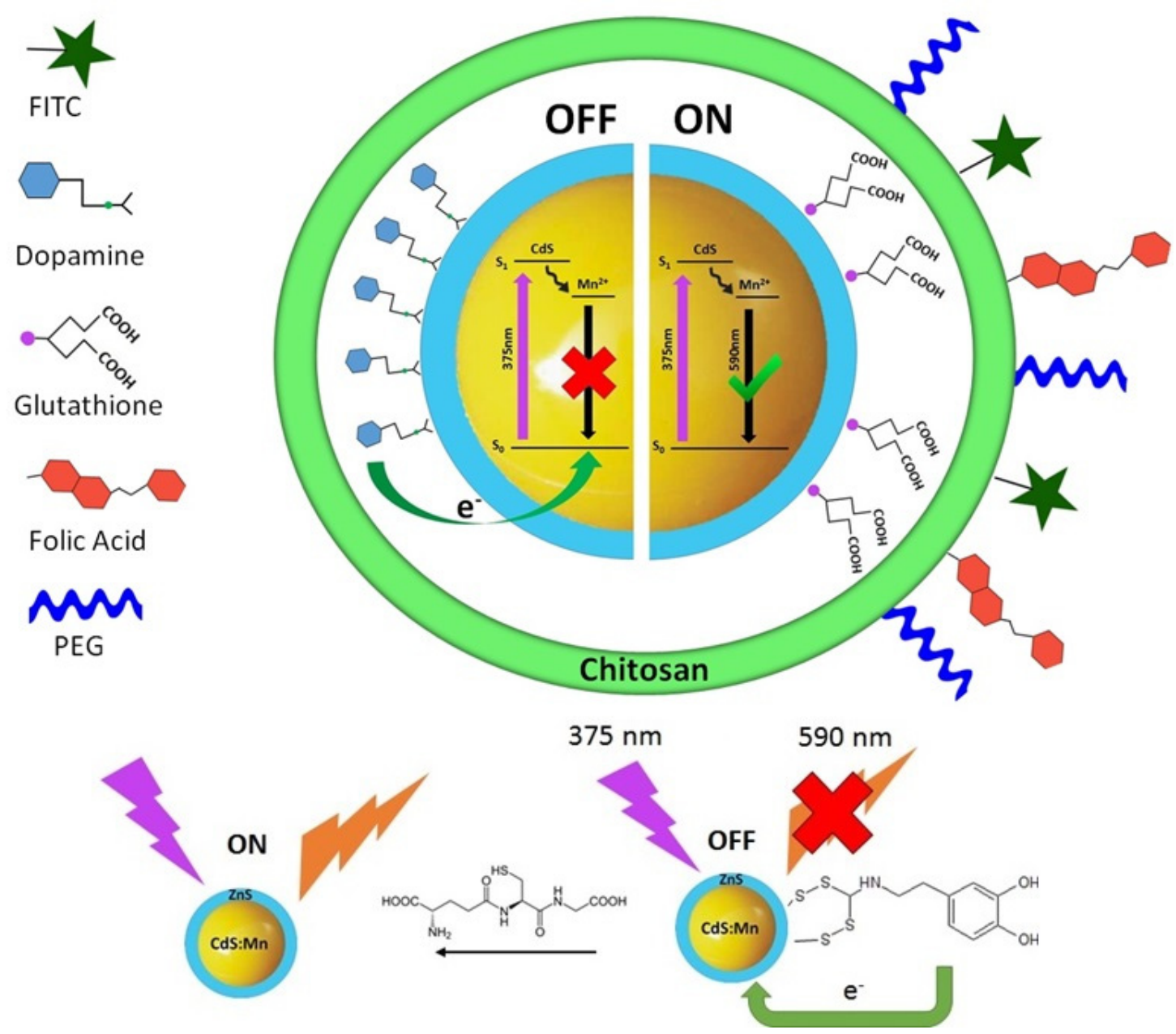

Scheme 1. Schematic representation of the overall design of the probe.

\subsection{Infrared Spectroscopy}

Due to the surfactant based Qdot synthesis, multiple washing steps were performed on the Qdots. Infrared spectroscopy was employed to determine the presence of bound dopamine and chitosan to the Qdots after washing and lyophilizing (Figure 1A). The peaks found at 1587 and $1380 \mathrm{~cm}^{-1}$ in the dopamine-Qdot conjugate, and the 1635 and $1384 \mathrm{~cm}^{-1}$ peaks observed for the full probe can be attributed to the stretching of $\mathrm{C}-\mathrm{C}$ bonds in the aromatic ring. These bands are not observed in the FTIR 
spectra of bare Qdots (not shown), indicating that dopamine is present on the Qdot surface after washing. C-O stretching vibrations of chitosan were observed for the full probe at $1071 \mathrm{~cm}^{-1}$, as reported in literature [40,41]. This absorption masks the absorption of dopamine hydroxyl groups, since chitosan is present at higher concentrations in the probes. Absorption peaks characteristic of the isocyanate bond between FITC and chitosan were observed at 1562, 1395, and $1002 \mathrm{~cm}^{-1}$ (Figure S1) [42]. These observations confirm the presence of FITC after washing.
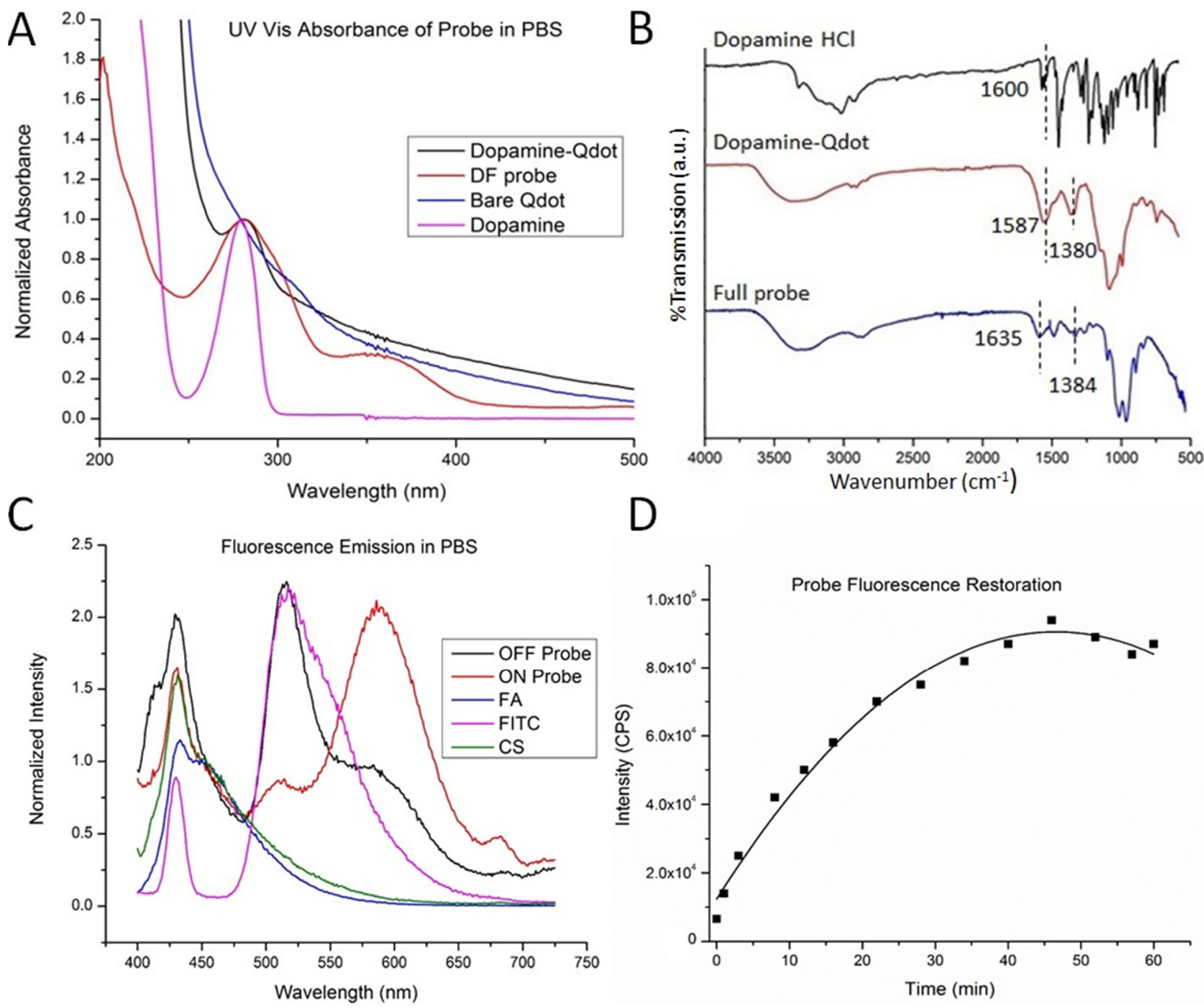

Figure 1. (A) UV-vis absorbance of dopamine $\mathrm{HCl}$, bare $\mathrm{CdS}: \mathrm{Mn} / \mathrm{ZnS}$ Qdots, dopamine-Qdot conjugate, and the full probe. The peak at $278 \mathrm{~nm}$ is attributed to absorption by dopamine. This peak is evidence of dopamine remaining bound to the Qdot surface after washing and coating with chitosan; (B) FTIR spectra of dopamine $\mathrm{HCl}$, dopamine-Qdot conjugate, and the full probe; $(\mathbf{C})$ Normalized fluorescence emission spectra of the full probe in the "OFF" state, the full probe in the "ON" state (Probe $+10 \mathrm{mM}$ glutathione (GSH)), folic acid (FA), Fluorescein isothiocyanate (FITC), and hydrothermally treated chitosan (CS) in PBS buffer obtained with $375 \mathrm{~nm}$ excitation; (D) Fluorescence intensity of Qdots in PBS over time after addition of $10 \mathrm{mM} \mathrm{GSH}$. Full restoration of Qdots is observed $40 \mathrm{~min}$ after addition of GSH. This shows the extent to which fluorescence can be restored for the probe. A polynomial function was fitted to the data to determine the linearity of fluorescence restoration. 


\subsection{UV-Vis Spectroscopy}

The optical properties of the probe were characterized by UV-Vis absorption and fluorescence spectroscopy. Figure 1B shows the UV-Vis absorbance spectra of the probe and Qdots acquired with water as the solvent. An absorption peak was observed at $278 \mathrm{~nm}$ that was assigned to dopamine [43]. This peak was found in both spectra of the dopamine-Qdot conjugate and the full probe. These spectra show that dopamine remains on the Qdot surface after rigorous washing. The strength of the interaction is due to the potential for dopamine dithiocarbamate to form two disulfide bonds with the Qdot surface in a bidentate fashion [32]. This makes the Qdot-dopamine bond more stable and helps prevent premature displacement from the Qdot surface by media proteins.

\subsection{Fluorescence Spectroscopy}

Fluorescence emission spectra of the full probe and the individual constituent components were collected under $375 \mathrm{~nm}$ excitation with buffer as the solvent (Figure 1C). The emission peak at $450 \mathrm{~nm}$ is attributed to a combination of chitosan and folic acid fluorescence [44]. The peak at $490 \mathrm{~nm}$ is due to FITC bound to chitosan, and the peak observed at $590 \mathrm{~nm}$ is the Qdot fluorescence. All of these emission peaks are present in the spectra of the full probe indicating that all the components have been successfully bonded as any unbound reagent would be washed off. The full probe was treated with $10 \mathrm{mM} \mathrm{GSH}$ to turn it to the "ON" state; this is to simulate the environment of a cancer endosome. Ten millimolar GSH was then added to the probe, and fluorescence spectra were collected at 5 min intervals [45]. The concentration of GSH in blood plasma of humans was found to be less than $1 \mathrm{mM}$ in previous studies [46]. The change in intensity of the emission peak at $590 \mathrm{~nm}$ was then plotted as a function of time (Figure 1D). This restoration of fluorescence plateaued $40 \mathrm{~min}$ after GSH addition.

\subsection{Electron Microscopy}

Scanning Electron Microscopy (SEM) analysis was used in conjunction with SEM Energy Dispersive Spectroscopy (EDS) to analyze the size and morphology of the full probe and show the presence of Qdots in the chitosan/Qdot composite. Figure 2 shows a SEM image of the probe. The Qdots were too small to be resolved, however, EDS shows the presence of cadmium. The hydrothermal treatment and filtration of the chitosan prior to mixing with the quantum dot shows mostly small chitosan particles remaining. A wide range of sizes of the full probe was observed with the average size falling near $1 \mathrm{mn}$ in diameter. Many large particles were observed due to aggregation of the particles while coating the SEM grid, and the high efficiency of the CNBr cross-linking of chemistry. Transmission Electron Microscopy (TEM) analysis performed on bare Qdots shows monodisperse spheres with diameters ranging from 3.5 to $5.0 \mathrm{~nm}$ (Figure 3A). The TEM images were analyzed to find the particle distribution (Figure 3B). Single Qdots were identified by their characteristic lattice lines observed in the TEM. Dynamic Light Scattering (DLS) data on the full probe (Figure 3C) showed an average size of $380 \mathrm{~nm}$ following sonication, which is probably more representative of the probe in a moderately dispersed state compared to the SEM results. 

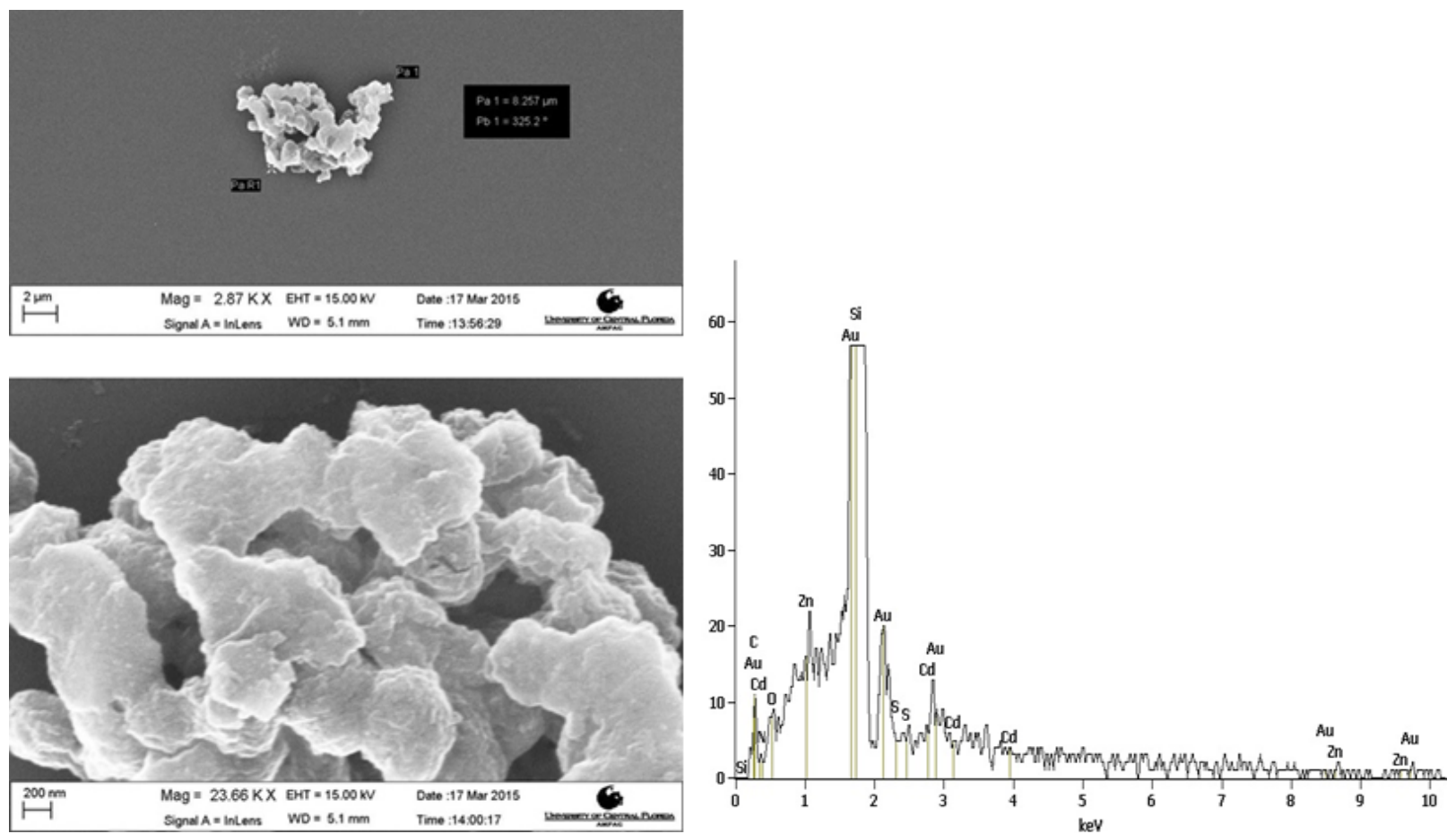

Figure 2. Scanning Electron Microscopy (SEM) images and Energy Dispersive Spectroscopy (EDS) spectrum of the gel probe. The full probe is composed of small particles that are embedded in a cross-linked chitosan matrix. The particle pictured above could possibly be multiple aggregated particles. The EDS spectrum shows small peaks for cadmium and zinc, which confirm the presence of Qdots in the chitosan matrix.

A
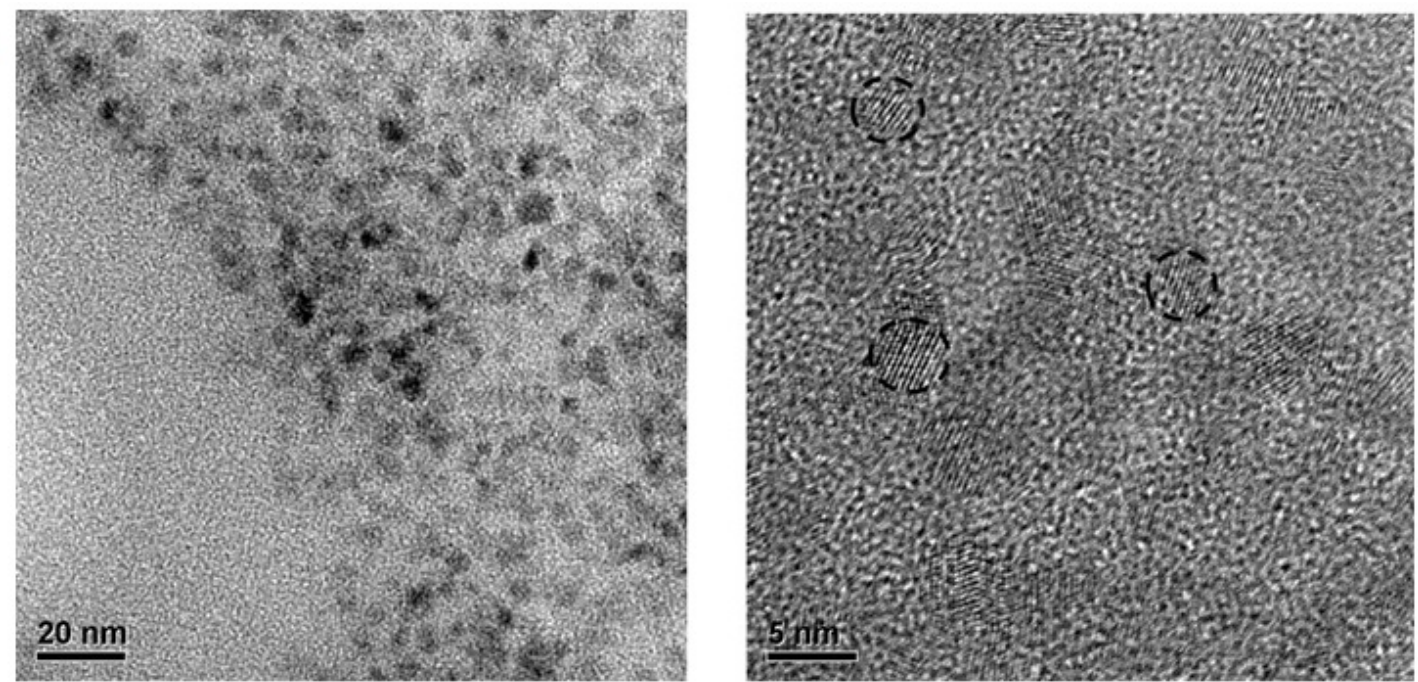

Figure 3. Cont. 

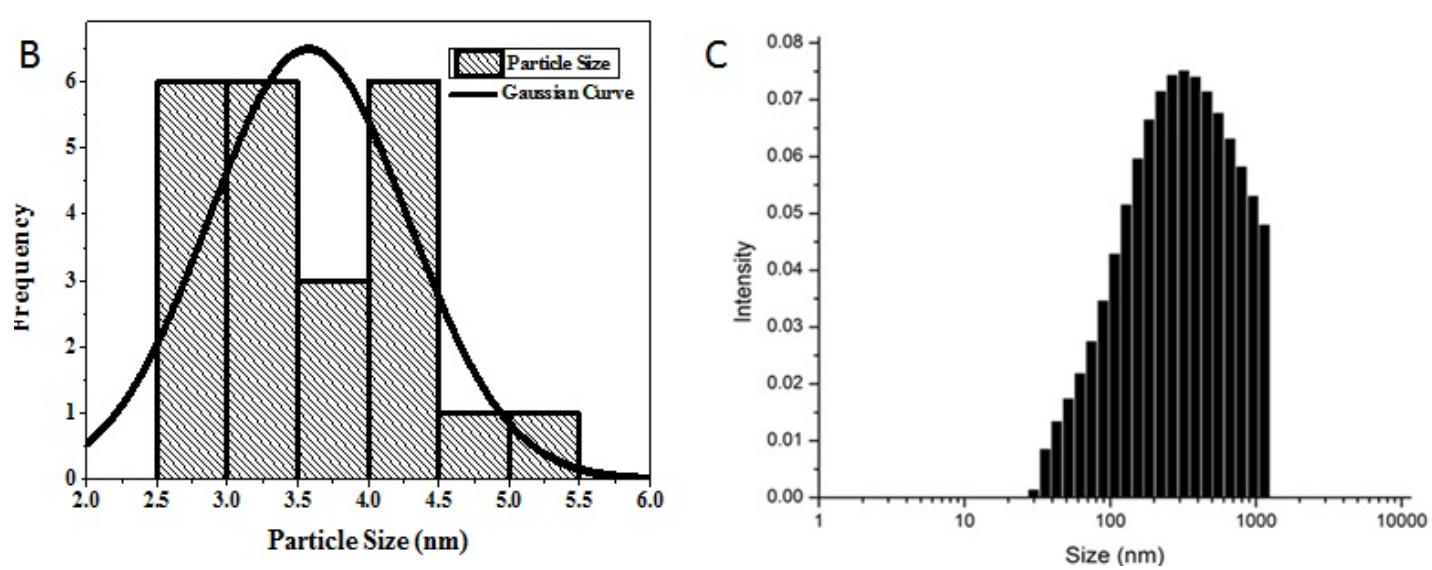

Figure 3. (A) Transmission Electron Microscopy (TEM) images of the bare CdS:Mn/ZnS Qdots. Three Qdots are circled for clarity in the image on the right; (B) The Qdot size distribution as determined by the observation of the lattice planes of 23 of the most clearly observed individual Qdots. Data were taken from multiple images (not shown). A normal distribution was fitted to the data to determine the average Qdot size; (C) Size distribution of the full probe dispersed in water as measured by DLS. The size scale is logarithmic. The apparent cutoff on the right hand side of the histogram is due to the absence of particles with diameter greater than $2000 \mathrm{~nm}$.

\subsection{Cytotoxicity}

To test the biocompatibility of the full probe and its components, bare Qdots as well as the full probe were applied to OVCAR3, TE71, J774a.1, and RAW264.7 cells in a 96 well plate, and a cell proliferation assay (MTS assay) was performed after $24 \mathrm{~h}$ incubation. Macrophages are known to rapidly internalize large particles of dust or bacteria cells. For a Qdot based probe to be applicable for biological research, it would need to either bypass internalization by macrophages and/or be nontoxic to them as they are present in most multicellular organisms. MTS assay (formazan dye) was used to assess the toxicity of the full probe with these three cell lines. MTS assay showed both bare Qdots and the full probe to be nontoxic to OVCAR3, TE71, and J774a.1 macrophage cells even at the highest concentration tested, $100 \mathrm{mg} / \mathrm{L}$ (Figure 4). To cross validate that the Qdots were not interacting with the MTS dye, an Alamar blue cell proliferation assay (Resazurin dye) was completed for the RAW264.7 macrophages at the same concentrations of Qdot and full probe (Figure S2).

The Alamar blue assay showed minimal cytotoxicity to the RAW264.7 macrophages, consistent with the MTS assay. The mild toxicity for J774a.1 and RAW2647 macrophages was thought to be due to increased internalization of the particles by these cell lines, and this is assessed later. The toxicity data obtained from the MTS assay are consistent with previous studies that have correlated various doses of $\mathrm{CdTe} / \mathrm{CdSe} \mathrm{Zn} / \mathrm{S}$ core-shell quantum dots with a variety of toxic response markers specific to cadmium-based nanomaterials [30,47]. The observed increase in viability for the highest doses of $+\mathrm{FA}$ probe for the $\mathrm{J774a}$.1 cells could be due to increases in mitochondrial reductase activity as recently reported [48-50]. 
A

TE71 Cytotoxicity

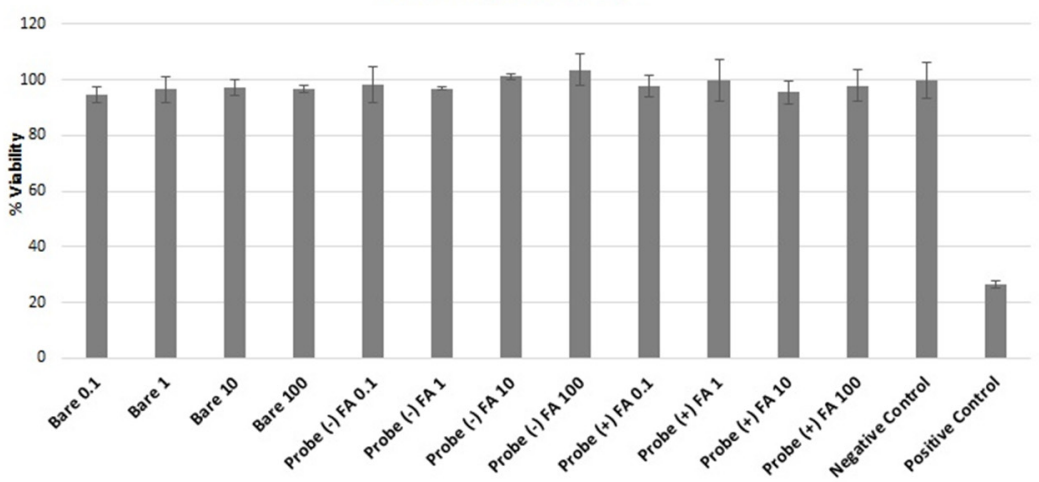

B OVCAR3 Cytotoxicity

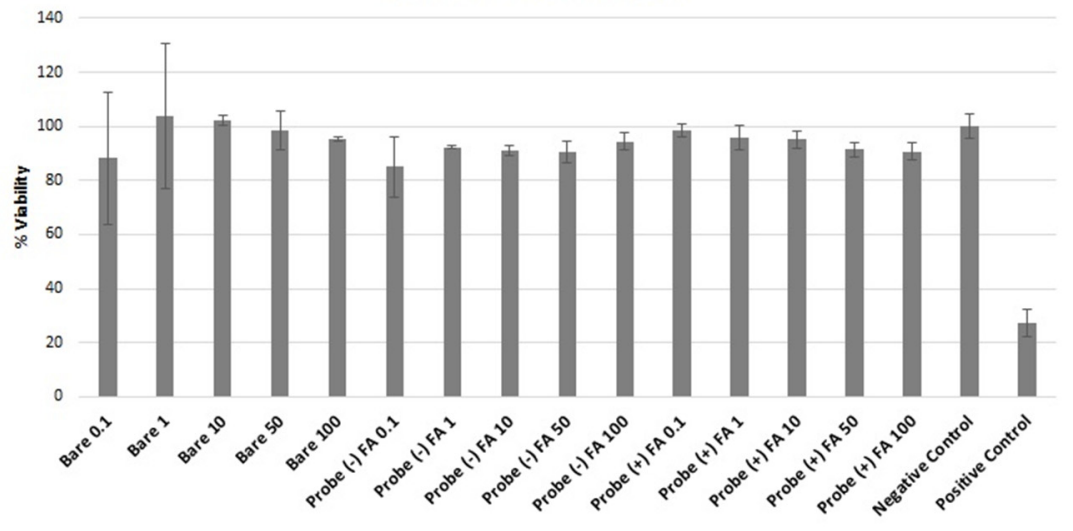

C J774a.1 Cytotoxicity

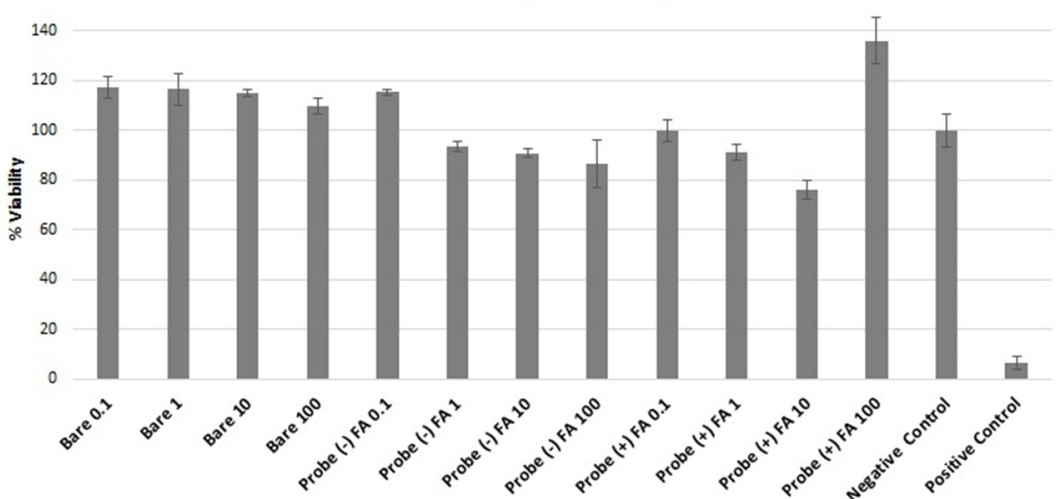

Figure 4. (A) Observed cytotoxicity towards TE71; (B) OVCAR3; and (C) J774a.1 macrophage cells after $24 \mathrm{~h}$ incubation with bare Qdots and the full probe as measured by MTS assay. Bare Qdots and full probe with folic acid (+) FA and without folic acid (-) FA bound to the chitosan at $100,10,1$, and $0.1 \mu \mathrm{g} / \mathrm{mL}$ Qdot concentration. The growth control (negative) is untreated cells in media. The positive control for cell death was completed by adding water to the cells. The cytotoxicity data are plotted relative to the negative control, which was assigned to have $100 \%$ viability. Error bars are standard deviation of the mean.

\subsection{Cell Uptake}

Preliminary cell uptake studies were performed to study the interaction of the particles with cells. (Figures 5-7). Studies have shown that some cancer cells such as OVCAR3 overexpress folate receptor proteins on their cell membranes [28,29]. Folate is essential for DNA synthesis and is used rapidly by 
fast dividing cancer cells. Overexpression of these receptors has been used as a biomarker for detecting cancer cells $[26,51,52]$. TE71 were used as a normal control cell line that does not overexpress folate receptors. J774a.1 murine monocytes were used as a cell line representative of systemic non-differentiated macrophages. These express folate receptors as well. Confocal images of the cells show that the full probe remained mostly bound to the cell surface. This observation is consistent for all cell lines, while some was internalized by the macrophages (Figure 7). The control cell lines not over-expressing folate receptors internalized similar amounts of folate $(+)$ and folate $(-)$ probe as expected (Figures 6 and 7). Both OVCAR3 and J774a.1 cells were observed to bind more of the probe that included conjugated folate (+ FA) on the cell surface. This effect was more pronounced in OVCAR3 than the other cell lines due to the increased number of receptors on the surface of OVCAR3 cells. The amount of probe bound in each circumstance is determined by the total Qdot and FITC fluorescence assessed visually.

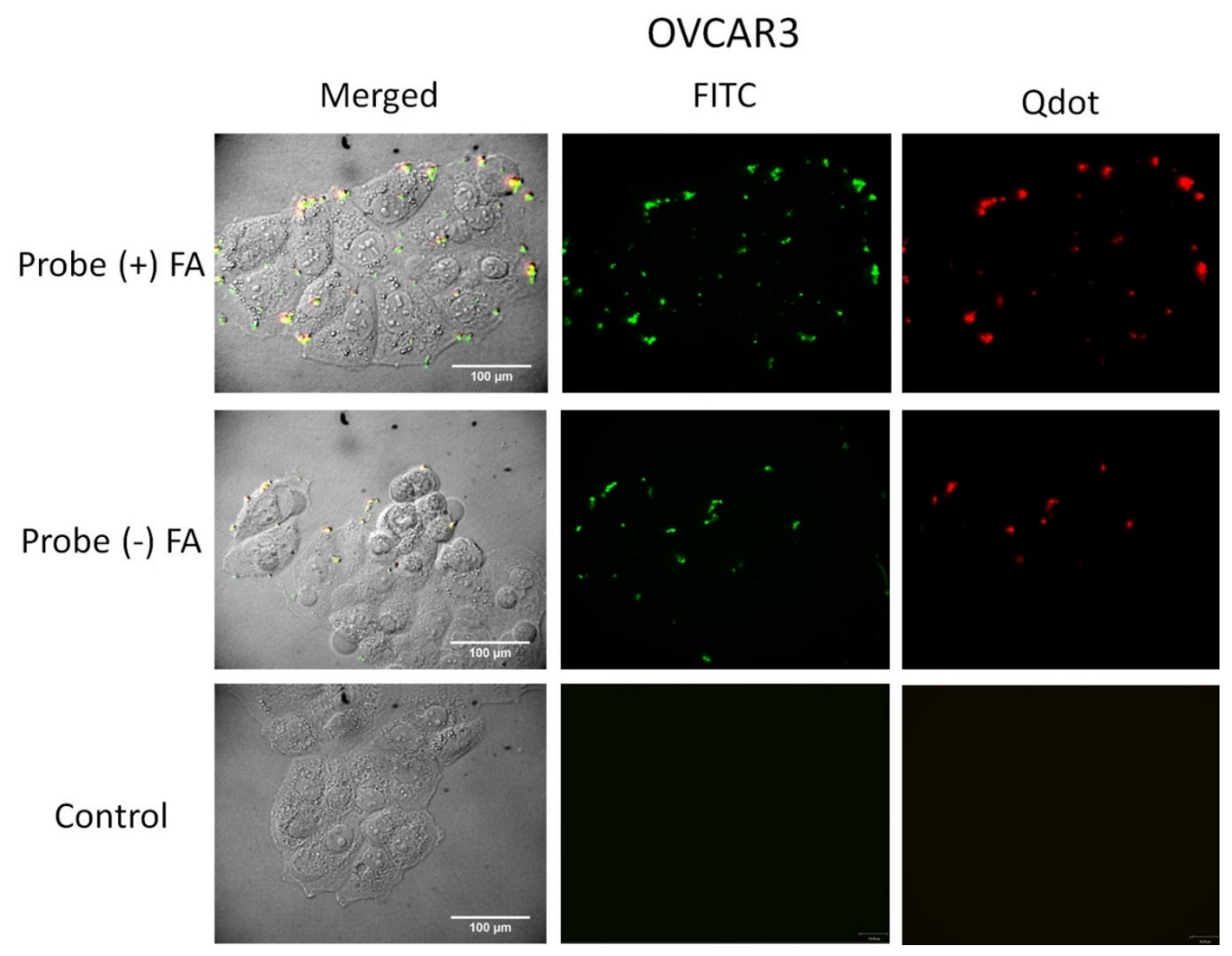

Figure 5. Confocal microscopy images of OVCAR3 cells incubated with the full probe with $(+)$ FA and without folic acid (-) FA, and with media without probe (control). The right column images display the fluorescence of the Qdots only. The middle column images show just the fluorescence from FITC. The left images are phase images merged with Qdot and FITC fluorescence images. Qdots fluorescence is seen co-localized with fluorescence of chitosan bound FITC. Increased binding of the probe to OVCAR3 cells was observed with samples containing attached folic acid (Probe (+) FA). The full Z-stack images can be viewed in the supplemental section (Figures S3-S6). 


\section{TE71}
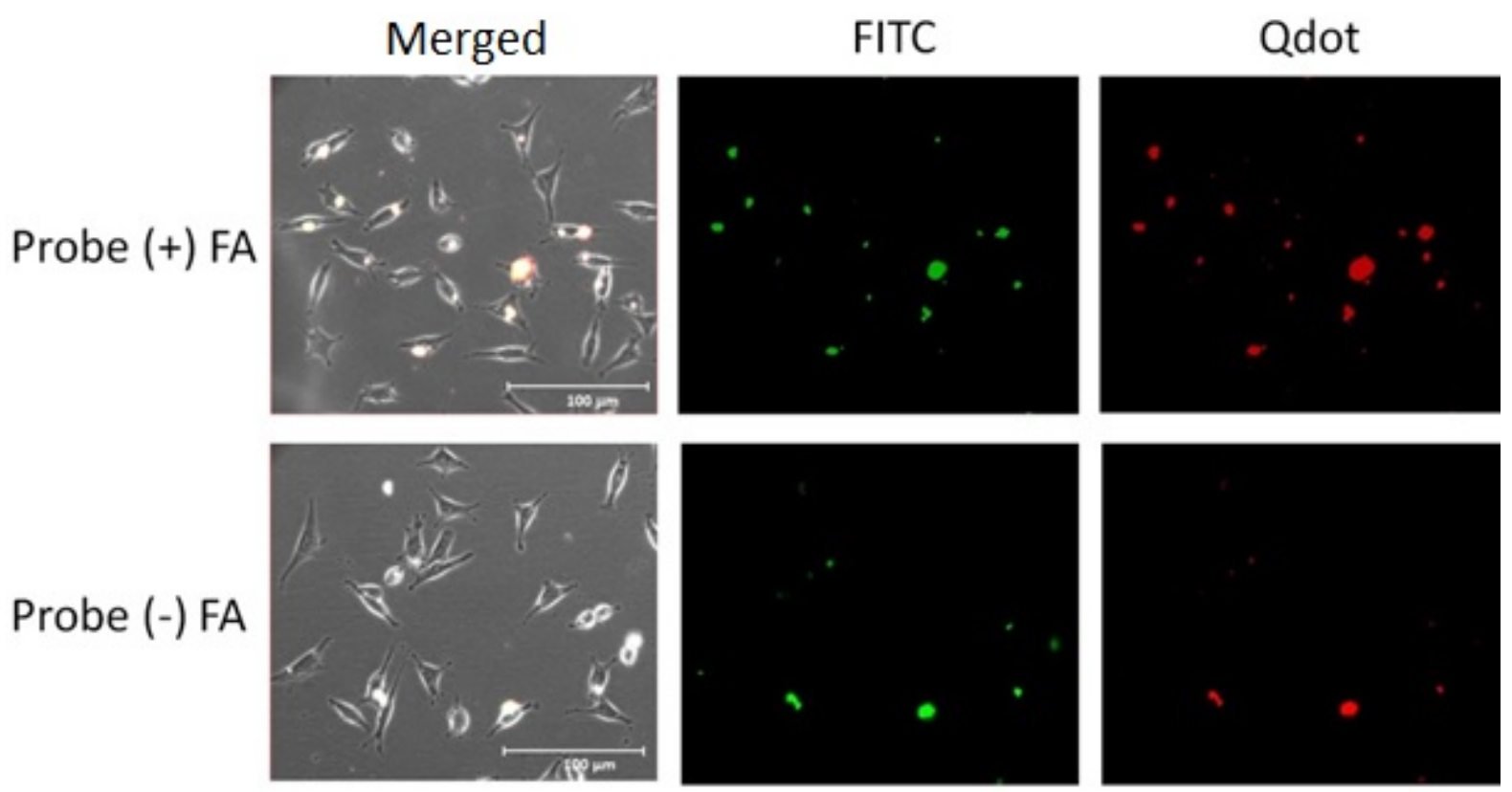

Control
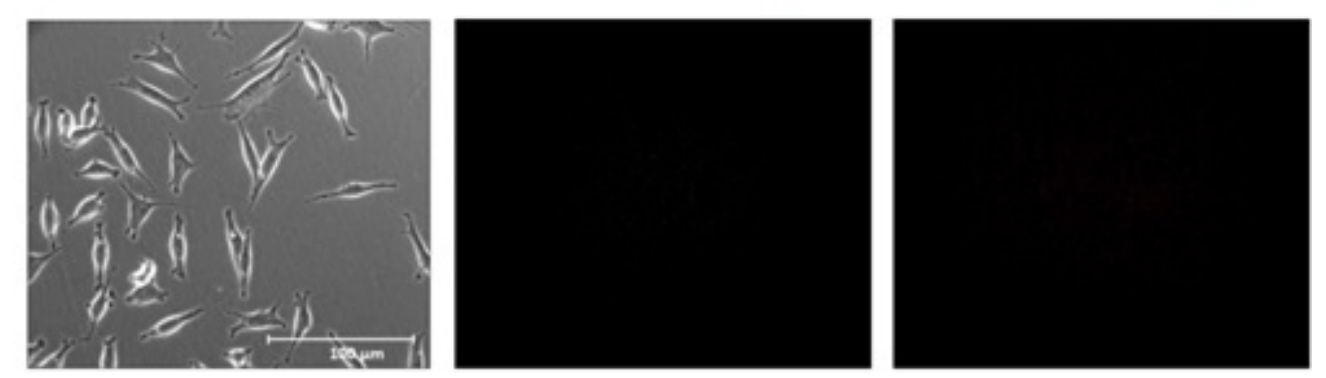

Figure 6. Fluorescence microscopy images of TE71 cells incubated with the probe with bound folic acid (+) FA and without folic acid (-) FA, and with media without probe (control). The left images are phase images merged with the fluorescence images. The middle images are only the FITC fluorescence. The right images are only the Qdot fluorescence. Only a small increase in binding of the full probe to the TE71 cells was seen from the probe $(+)$ FA. This is most likely because TE71 does have some folate receptors but has not been shown to overexpress them.

We noted significant internalization of the full probe by J774a.1 monocytes through confocal microscopy imaging for both the folate positive and folate negative probe (Figure 7). The J774a.1 mouse monocyte cells are known to express Fc gamma receptor sites on the extracellular domain of the cell membrane [53]. This folate receptor expression is a prime contributor to the observed macrophage internalization of folate positive probe $(+\mathrm{FA})$ via folate receptor specific pathway. Additionally, nonspecific endocytotic/phagocytotic pathways may be a contributor to the internalization of the folate negative probe (-FA). This pathway specific sensitivity is attributed to a variety of properties, such as size, shape, charge, and surface functionality of the probe [54-56].

The dependency of uptake on binding to folic acid receptors is shown in Figure 8 for OVCAR3 cells. The dependency of folate receptor interaction on the observed total full probe binding was analyzed through fluorescence and confocal microscopy. Cells were incubated with the full probe either with or 
without extra folic acid $(1 \mathrm{mM})$ added to the media. The presence of a large concentration of free folic acid in media has been previously shown to decrease the uptake of folate-conjugated particles since access to folate receptors becomes compromised as they become saturated with free folic acid [57]. The fluorescence intensity of the probe bound to cells incubated in folate media was much less than cells incubated with folate free media (Figure 8). These results suggest that folate receptors play a large part in the binding of the probe to the OVCAR3 cells.

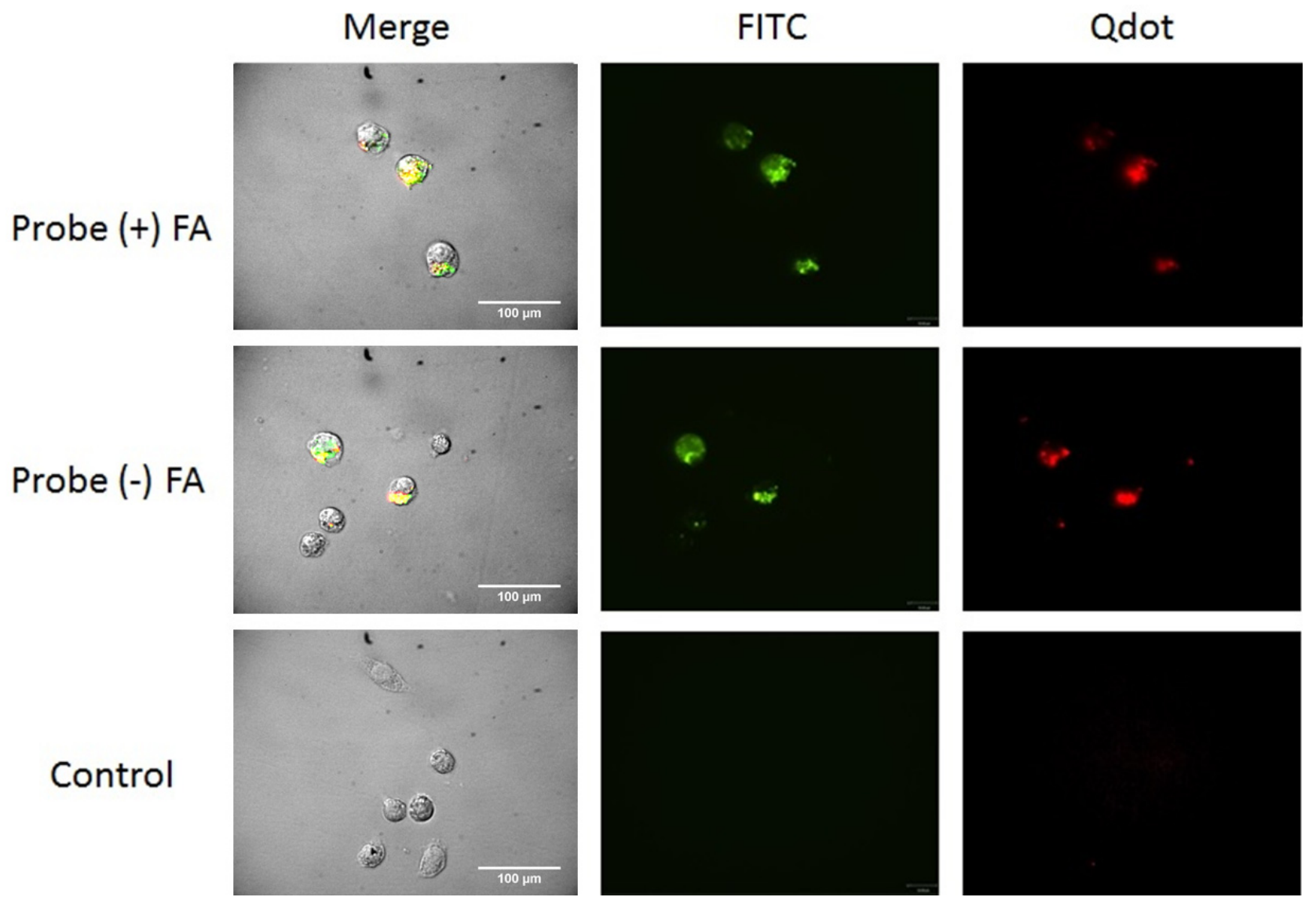

Figure 7. Confocal microscopy images of J774a.1 macrophage cells incubated with the full probe with (+) FA and without folic acid (-) FA, and with media without probe (control). The left images are merged phase and fluorescence images. The middle image are only FITC fluorescence and right images are only Qdot fluorescence. A large amount of the full probe was bound and some internalized by the cells. Macrophages are known to nonspecifically internalize particles which contribute largely to internalization of the probe by these cells. 


\section{OVCAR3 Probe Folate Binding}

Media

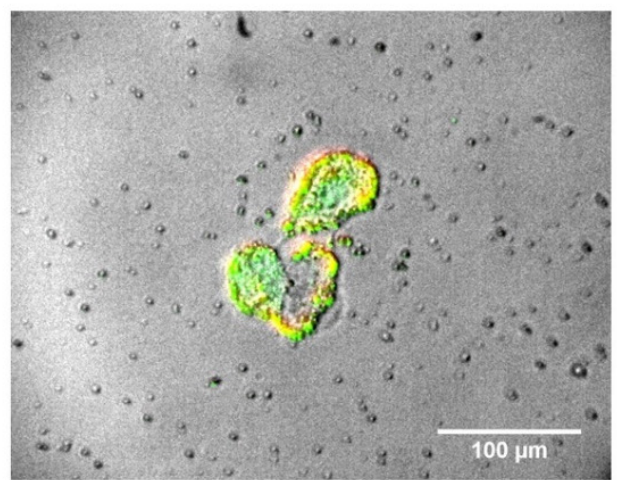

Probe (+) FA

Probe (-) FA

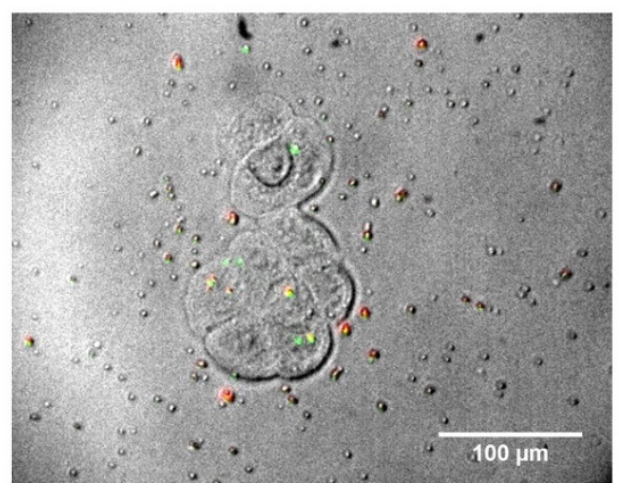

Media + 1mM folic acid
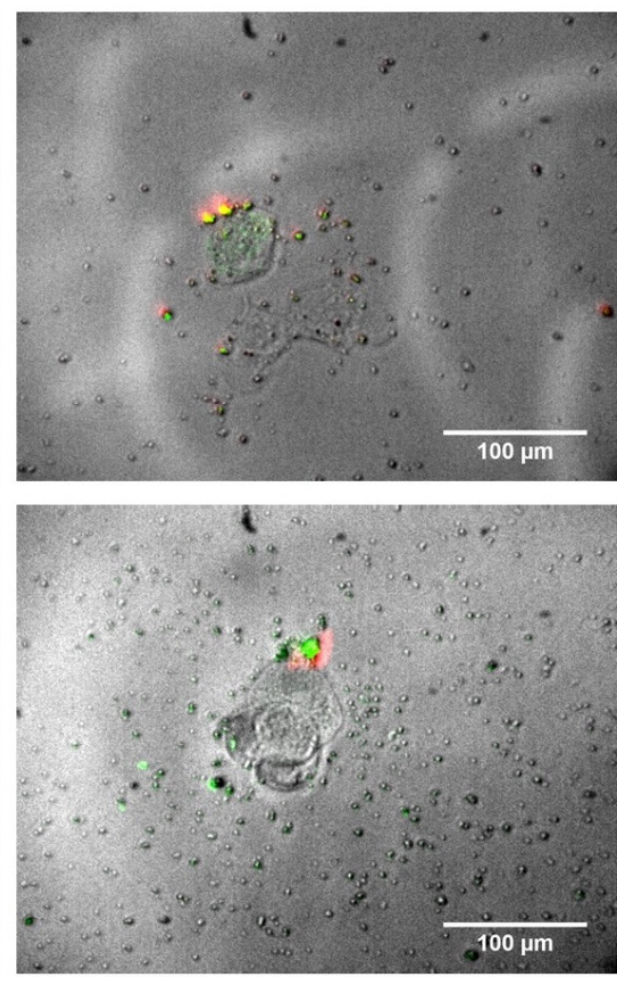

Figure 8. Fluorescence images of OVCAR3 cells after incubation with the full probe. (Left): Cells were incubated with regular DMEM media. (Right): Cells were incubated with media that had extra folic acid added $(1 \mathrm{mM})$. The high concentration of free folic acid binds to the folate receptors blocking them from interacting with the folic acid bound to the probe.

\section{Experimental Section}

\subsection{Materials}

Cadmium acetate dehydrate, manganese (II) acetate tetrahydrate, glutathione (GSH), and Dioctyl sodium sulfate (AOT) were all purchased from Acros Organics (Morris Plains, NJ, USA). Sodium Sulfide, zinc acetate dihydrate, dopamine hydrochloride, cyanogen bromide (CNBr), and low molecular weight chitosan were purchased from Sigma-Aldrich (St Louis, MO, USA). Fluorescein isothiocyanate (FITC), heptane, dimethylsulfoxide (DMSO), trimethylamine, methanol, ethanol, hydrochloric acid, and folic acid were purchased from Thermo Fisher Scientific (Waltham, MA, USA). Acetonitrile was obtained from Alfa Aesar (Ward Hill, MA, USA). Nanopure water was obtained from a Barnstead Nanopure Diamond Model \# D11911 (Thermo Scientific, Waltham, MA, USA). All materials were used as received at room temperature and without further purification. All solvents used were reagent grade and used as received. 


\subsection{Synthesis of Dopamine Coated CdS:Mn/ZnS Quantum Dots}

The Qdots were prepared from a micro-emulsion method using previously established protocol $[8,58]$ with additional modifications. Stock solutions of $266 \mathrm{mg}$ cadmium acetate dihydrate and $4.9 \mathrm{mg}$ manganese acetate tetrahydrate in $10 \mathrm{~mL}$ water, $257.5 \mathrm{mg}$ sodium sulfide in $5 \mathrm{~mL}$ water and $285.25 \mathrm{~g}$ zinc acetate dihydrate in $5 \mathrm{~mL}$ water were prepared. One hundred and seventy-five milliliters of a heptane and $15.49 \mathrm{~g}$ AOT solution was prepared and separated into three flasks, one with $25 \mathrm{~mL}$ and two with $75 \mathrm{~mL}$ each. Then, $0.9 \mathrm{~mL}$ of the cadmium solution was added to the $25 \mathrm{~mL}$ flask, and $2.7 \mathrm{~mL}$ of the sulfur and zinc were added to the $75 \mathrm{~mL}$ flasks. The flasks were covered and magnetically stirred for $1 \mathrm{~h}$. The cadmium flask was then slowly added to the sulfur flask and allowed to stir for $15 \mathrm{~min}$. The zinc flask was added dropwise $(2-3 \mathrm{~mL} / \mathrm{min}$ ) to the cadmium/sulfur flask to provide the $\mathrm{ZnS}$ shell layer. The Qdots were then covered and left to stir a week before use. Dopamine dithiocarbamate was synthesized by reaction of $104 \mathrm{mg}$ of dopamine hydrochloride with $160 \mu \mathrm{L}$ of $\mathrm{CS}_{2}, 200 \mu \mathrm{L}$ methanol and $50 \mu \mathrm{L}$ of $\mathrm{Et}_{3} \mathrm{~N}$ [32,33]. Three milliliters of the Qdots in micro-emulsion was then reacted with dopamine dithiocarbamate for $3 \mathrm{~min}$. The dopamine-Qdots were washed five times in ethanol to remove any unbound dopamine.

\subsection{Synthesis of Chitosan Coated Qdots}

Chitosan was first depolymerized by hydrothermal treatment as previously described [59]. Three hundred milligrams of chitosan was dissolved in $30 \mathrm{~mL}$ of $1 \%$ hydrochloric acid and transferred to a Teflon container, which was placed sealed in a steel container. Samples were heated at $150{ }^{\circ} \mathrm{C}$ for $90 \mathrm{~min}$. The chitosan was then filtered with a $0.22 \mu \mathrm{m}$ syringe filter and dialyzed for three days while changing the dialysis water every $8 \mathrm{~h}$ to bring the $\mathrm{pH}$ to neutral and remove the chlorine ions. The chitosan was then filtered again with a $0.22 \mu \mathrm{m}$ syringe filter. The sample was then frozen and lyophilized for use as coating. Chitosan coating for the probe was accomplished by mixing solutions of $3 \mathrm{mg}$ of lyophilized hydrothermally treated chitosan, $0.6 \mathrm{mg}$ folic acid, $0.6 \mathrm{mg}$ FITC, and $1.2 \mathrm{mg}$ PEG in $3 \mathrm{~mL}$ PBS for $1 \mathrm{~h}$. The same coating solution was prepared without folic acid for the (-FA) probe. This coating was then mixed with the dopamine-Qdot conjugate in the sonicator for $1 \mathrm{~h}$. Three milligrams of $\mathrm{CNBr}$ in $15 \mu \mathrm{L}$ acetonitrile was added and allowed to react for $20 \mathrm{~s}$ for cross-linking the polymer and Qdots. The coated Qdots were then washed 4 times with ethanol to remove any unbound coating and dye.

\subsection{FTIR Experiments}

The FTIR spectra of the full probe and components were collected using a PerkinElmer Spectrum 100 Series ATR FT-IR Spectrometer (PerkinElmer, Waltham, MA, USA). All samples were frozen in DI water or DMSO and lyophilized (FreeZone 4.5 L Freeze Dry System, Labconco, Kansas City, MO, USA) to dry powder prior to analysis.

\subsection{Solution Spectroscopy}

UV-Visible absorbance spectroscopy was employed using a Cary $300 \mathrm{UV}$-Vis Spectrophotometer (Agilent, Santa Clara, CA, USA). The solvent used was $1 \times$ PBS in a $1 \mathrm{~cm}$ quartz cuvette. Concentrations 
of the samples were standardized to adjust for batch-to-batch differences in concentration by adjusting their absorbance at $375 \mathrm{~nm}$ to 0.05 . Fluorescence spectra were collected on a NanoLog Fluorescence Spectrophotometer (SPEX, Jobin Yvon Horiba, Edison, NJ, USA). The probe was treated with $10 \mathrm{mM}$ GSH to simulate the effect of GSH binding inside the cell to turn the probe ON. The excitation wavelength used was $375 \mathrm{~nm}$ as it has maximum absorption by the Qdots.

\subsection{Scanning Electron Microscopy (SEM)}

Samples for SEM were dispersed in water and spin coated onto a silica wafer. They were then gold coated for one minute. Samples were analyzed by a Zeiss ULTRA-55 FEG SEM (Zeiss, Oberkochen, Germany) equipped wit/h a Noran System 7 EDS with Silicon Drift Detector (Thermo Scientific, Madison, WI, USA).

\subsection{Dynamic Light Scattering (DLS)}

DLS measurements were preformed using a PDDLS/Cool/Batch 40 T Precision Detector (Chia Yun Instrument Inc., Taipei City, Taiwan). Data was processed using Precision Deconvolve software (Precision Detectors Inc., Bellingham, MA, USA).

\subsection{Cytotoxicity}

TE71 (mouse thymus epithelial ATCC), OVCAR3 (human ovarian cancer ATCC), and J774a.1 (BALB/c mouse monocyte cell line, ATCC) cells were grown in Dulbecco's modified Eagles's medium (DMEM, Corning, NY, USA) with 10\% heat-inactivated fetal bovine serum (20\% for OVCAR3 cells). The cells seeded at a density of 40,000 cells per well onto a 96-well plate (Cellstar, Sigma-Aldrich, St. Louis, MO, USA). Cells were then incubated $24 \mathrm{~h}$ and washed with PBS. The cells were then treated with Qdots and probe for $24 \mathrm{~h}$, after which a background absorption spectra of the plate was taken at $490 \mathrm{~nm}$ (BioTek ELx808 absorbance plate reader (BioTek Instruments, Winooski, VT, USA) and the MTS dye (CellTiter 96 Aqueous One Solution Cell Proliferation Assay, Fisher Scientific (Thermo Fisher Scientific, Waltham, MA, USA) was applied. Cells were incubated $1-2 \mathrm{~h}$ at $37{ }^{\circ} \mathrm{C}$ and $5 \% \mathrm{CO}_{2}$, and the absorption of the MTS dye was again taken at $490 \mathrm{~nm}$. The background absorption of the particles was subtracted from absorption of the dye. Percentage of viability was calculated by dividing the samples by the absorbance of MTS dye for cells in growth media.

For Alamar blue assay, macrophages were seeded in a 96 well plate at the density of $2 \times 10^{4}$ cells/well using DMEM medium (10\% FBS) and incubated at $37^{\circ} \mathrm{C}$ and $5 \% \mathrm{CO}_{2}$ for overnight growth. Then, the medium was replaced by fresh medium before adding Qdots and full probe samples. After $24 \mathrm{~h}$ of incubation at $37{ }^{\circ} \mathrm{C}$ and $5 \% \mathrm{CO}_{2}$, the medium was again replaced and the Alamar blue reagent was added. The plate was incubated for an additional $3 \mathrm{~h}$ and the fluorescence was read at $590 \mathrm{~nm}$ emission (550 nm of excitation). Cell viability was calculated by dividing the fluorescence for samples by the fluorescence for cells in growth media (negative control). 


\subsection{Cell Uptake Studies}

TE71, OVCAR3, and J774a.1 macrophage cells were cultured in DMEM/F-12 media (Corning) with $10 \%$ heat inactivated FBS (OVCAR3 20\%) in $25 \mathrm{~cm}^{2}$ treated cell culture flasks (Cellstar) at $37{ }^{\circ} \mathrm{C}$ and $5 \% \mathrm{CO}_{2}$. OVCAR3 cells were cultured in the same way while using $20 \%$ heat inactivated FBS. Cell viability was determined using Trypan blue dye exclusion assay (Thermo-Fisher Scientific, Waltham, MA, USA) and cells were counted with a hemocytometer (Hausser Scientific Partnership, Horsham, PA, USA) after trypsinization. Only cell cultures with viability greater or equal to $95 \%$ were used. Cells were seeded onto a petri dish (Corning $35 \mathrm{~mm} \times 10 \mathrm{~mm}$ tissue-culture treated) at a density of $100,000 \mathrm{cell} / \mathrm{cm}^{2}$. The dish was incubated for $24 \mathrm{~h}$ at $37{ }^{\circ} \mathrm{C}$ and $5 \% \mathrm{CO}_{2}$. The cells were washed 5 times with HBSS and the media was replaced with the sample in DMEM/F-12 with 10\% FBS at a concentration of $10 \mathrm{mg} / \mathrm{L}$ (Qdot concentration). Cells with no probe added were imaged as a control. The cells were incubated for $3 \mathrm{~h}$ and then washed five times with PBS to remove any particles that were not bound or internalized by the cells. The cells were then fixed with $4 \%$ paraformaldehyde (Electron Microscopy Sciences, Hatfield, PA, USA) before imaging and washed two more times. Approximately 15-20 fields of view were assessed with 10 cells per field, accounting for nearly $75 \%$ of the total occupied surface area. Average representative images were taken (Figures 5-8) to visually assess overall binding/uptake of probe. This experiment was repeated three times with independently synthesized samples, all yielding similar results.

\subsection{Fluorescence Spectroscopy}

Fluorescence images were taken using Olympus IX71 epiluminescence microscope with a LUCPlanFLN 60×/0.70 ph2 objective lens (/0.1-1.3/FN22) (Olympus, Tokyo, Japan). Images were captured by Andor Zyla sCMOS (DG-152V-C1E-FI) camera (Andor, Oxford Instruments, Belfast, UK) with Micro-Manager 1.4 version software. Mercury lamp was used as an excitation source for FITC and Qdot fluorescence. For FITC images, excitation, dichroic mirror and emission filters (491/10 nm, $510 \mathrm{dclp}, 514$ ref, respectively) were used. For Qdot images, excitation dichroic mirror and emission filters were used respectively 360/40, 4051p, 585/20. The images were overlaid with ImageJ software (NIH, Bethesda, MD, USA).

\subsection{Confocal Imaging}

Confocal images were acquired using a Zeiss Axioskop 2 plus upright microscope (Zeiss, Oberkochen, Germany) with a $40 \times$ water immersion objective. Fluorescence pictures were captured with a Hamamatsu ORCA-Flash4.0 camera (Hamamatsu Photonics, Tokyo, Japan) using PerkinElmer Volocity software (PerkinElmer, Waltham, MA, USA). Qdot pictures were taken with 365/10 nm excitation filter using a fluorescence lamp (X-Cite 120Q) with 607/45 nm emission filter (Excelitas Technologies, Waltham, MA, USA). Excitation of FITC was accomplished using $488 \mathrm{~nm}$ Melles Griot laser (643-PERYB-AO2) with a 525/50 emission filter (CVI Laser Optics, Albuquerque, NM, USA). Samples were scanned a total $50 \mu \mathrm{M}$ thickness with a $2 \mu \mathrm{M}$ step size. ImageJ software $(\mathrm{NIH}$, Bethesda, MD, USA) was used to further process the images. 


\section{Conclusions}

A multifunctional chitosan-quantum dot (Qdot) composite based nanogel probe was designed and synthesized. A one-step cross-linking of multiple components with $\mathrm{CNBr}$ chemistry was described. The design of the probe is novel in that it is based on a piggyback system employing activatable Qdots and chitosan gel for multimodal applications. Systematic spectroscopic and microscopic studies were completed to characterize the activatable (“OFF"/“ON”) biosensing properties, drug delivery (using dopamine as a model drug as well as Qdot fluorescence quencher), and folic acid mediated cancer targetability. The probe was found to be nontoxic and could readily bind to cancer cells, normal cells, and macrophages. Folic acid linked to the chitosan was observed to enhance binding in OVCAR3 cells due to elevated folate receptor expression. Additional experiments on drug delivery and cellular uptake are being carried out with an anti-cancer drug and will be published in the near future.

\section{Supplementary Materials}

Supplementary materials can be accessed at: http://www.mdpi.com/2079-4991/5/4/2359/s1.

\section{Acknowledgments}

We would like to acknowledge the National Science Foundation (NSF CBET grant \#1159500). Authors acknowledge Kirk Scammon of "Material Characterization Facility" of UCF Advanced Materials Processing and Analysis Center for his assistance with the SEM sample preparation.

\section{Author Contributions}

Swadeshmukul Santra conceived the idea of the nanoprobe design and synthesis strategy. Andre Gesquiere and Santra contributed to probe characterization plan including systematic probe characterization, in vitro studies and reproducibility research data. Jeremy Tharkur helped to refine the synthesis protocol of the probe. Tyler Maxwell performed the synthesis and physical/optical characterization of the probe. Maria Campos assisted with cell culturing experiments. Tahmina Banu and Edward Price performed the cell culturing and cytotoxicity experiments as well as analysis of results. Tyler Maxwell took the confocal images and along with Tahmina Banu and Edward Price took fluorescence microscope images and analyzed the results. Tyler Maxwell wrote the paper.

\section{Conflicts of Interest}

The authors declare no conflict of interest.

\section{References}

1. Yong, K.-T. Mn-doped near-infrared quantum dots as multimodal targeted probes for pancreatic cancer imaging. Nanotechnology 2009, 20, doi:10.1088/0957-4484/20/1/015102.

2. Vengala, P.; Dasari, A.; Yeruva, N. Quantum dots for drug delivery and therapy. Int. J. Pharm. Technol. 2012, 4, 2055-2074. 
3. Soltani, N.; Gharibshahi, E.; Saion, E. Band gap of cubic and hexagonal CdS quantum dots-Experimental and theoretical studies. Chalcogenide Lett. 2012, 9, 321-328.

4. Sapsford, K.E.; Pons, T.; Medintz, I.L.; Mattoussi, H. Biosensing with luminescent semiconductor quantum dots. Sensors 2006, 6, 925-953.

5. Smith, A.M.; Duan, H.; Mohs, A.M.; Nie, S. Bioconjugated quantum dots for in vivo molecular and cellular imaging. Adv. Drug Deliv. Rev. 2008, 60, 1226-1240.

6. Hoshino, A.; Manabe, N.; Fujioka, K.; Suzuki, K.; Yasuhara, M.; Yamamoto, K. Use of fluorescent quantum dot bioconjugates for cellular imaging of immune cells, cell organelle labeling, and nanomedicine: Surface modification regulates biological function, including cytotoxicity. J. Artif. Organs 2007, 10, 149-157.

7. Tharkur, J.; Telbum, A.; Basumallick, S.; Sah, R.; Catarero, K.; Maity, N.; Rifai, S.; Doshi, M.; Gesquiere, A.J.; Santra, S. Probing intra-cellular drug release event using activatable (OFF/ON) CdS:Mn/ZnS quantum dots (Qdots): Spectroscopic studies to investigate interaction of Qdots with quencher. Proc. SPIE 2013, 8596, doi:10.1117/12.2008983.

8. Mitra, R.N.; Doshi, M.; Zhang, X.; Tyus, J.C.; Bengtsson, N.; Fletcher, S.; Page, B.D.G.; Turkson, J.; Gesquiere, A.J.; Gunning, P.T.; et al. An activatable multimodal/multifunctional nanoprobe for direct imaging of intracellular drug delivery. Biomaterials 2012, 33, 1500-1508.

9. Santra, S. The potential clinical impact of quantum dots. Nanomedicine 2012, 7, 623-626.

10. Enkin, N.; Wang, F.; Sharon, E.; Albada, H.B.; Willner, I. Multiplexed analysis of genes using nucleic acid-stabilized silver-nanocluster quantum dots. ACS Nano 2014, 8, 11666-11673.

11. Park, J.; Park, Y.; Kim, S. Signal Amplification via Biological Self-Assembly of Surface-Engineered Quantum Dots for Multiplexed Subattomolar Immunoassays and Apoptosis Imaging. ACS Nano 2013, 7, 9416-9427.

12. Tan, Y.F.; Chandrasekharan, P.; Maity, D.; Yong, C.X.; Chuang, K.-H.; Zhao, Y.; Wang, S.; Ding, J.; Feng, S.-S. Multimodal tumor imaging by iron oxides and quantum dots formulated in poly (lactic acid)-D-alpha-tocopheryl polyethylene glycol 1000 succinate nanoparticles. Biomaterials 2011, 32, 2969-2978.

13. Erogbogbo, F.; Yong, K.-T.; Hu, R.; Law, W.-C.; Ding, H.; Cang, C.-W.; Prasad, P.N.; Swihart, M.T. Biocompatible Magnetofluorescent Probes: Luminescent Silicon Quantum Dots Coupled with Superparamagnetic Iron(III) Oxide. ACS Nano 2010, 4, 5131-5138.

14. Lee, J.-H.; Schneider, B.; Jordan, E.K.; Liu, W.; Frank, J.A. Synthesis of complexable fluorescent superparamagnetic iron oxide nanoparticles (FL SPIONs) and cell labeling for clinical application. Adv. Mater. 2008, 20, 2512-2516.

15. Trehin, R.; Figueiredo, J.-L.; Pittet, M.J.; Weissleder, R.; Josephson, L.; Mahmood, U. Fluorescent nanoparticle uptake for brain tumor visualization. Neoplasia 2006, 8, 302-311.

16. Yang, K.; Zhu, L.; Nie, L.; Sun, X.; Cheng, L.; Wu, C.; Niu, G.; Chen, X.; Liu, Z. Visualization of protease activity in vivo using an activatable photo-acoustic imaging probe based on $\mathrm{CuS}$ nanoparticles. Theranostics 2014, 4, 134-141.

17. Chen, N.-T.; Cheng, S.-H.; Liu, C.-P., Souris, J.S.; Chen, C.-T; Mou, C.-Y.; Lo, L.-W. Recent advances in nanoparticle-based foerster resonance energy transfer for biosensing, molecular imaging and drug release profiling. Int. J. Mol. Sci. 2012, 13, 16598-16623. 
18. Gui, R.; Wan, A.; Zhang, Y. Ratiometric and Time-Resolved Fluorimetry from Quantum Dots Featuring Drug Carriers for Real-Time Monitoring of Drug Release in situ. Anal. Chem. 2014, $86,5211-5214$.

19. Banerjee, S.; Kar, S.; Perez, J.M.; Santra, S. Quantum Dot-Based OFF/ON Probe for Detection of Glutathione. J. Phys. Chem. C 2009, 113, 9659-9663.

20. Ji, X.; Wang, W.; Mattoussi, H. Effects of separation distance on the charge transfer interactions in quantum dot-dopamine assemblies. Phys. Chem. Chem. Phys. 2015, 17, 10108-10117.

21. Ji, X.; Palui, G.; Avellini, T.; Na, H.B.; Yi, C.; Knappenberger, K.L.; Mattoussi, H. On the pH-Dependent Quenching of Quantum Dot Photoluminescence by Redox Active Dopamine. J. Am. Chem. Soc. 2012, 134, 6006-6017.

22. Kwon, Y.-T.; Choi, Y.-M.; Kim, K.-H.; Lee, C.-G.; Lee, K.-J.; Kim, B.-S.; Choa, Y.-H. Synthesis of $\mathrm{CdSe} / \mathrm{ZnSe}$ quantum dots passivated with a polymer for oxidation prevention. Surf. Coat. Technol. 2014, 259, 83-86.

23. Negele, C.; Haase, J.; Budweg, A.; Leitenstorfer, A.; Mecking, S. Stable Single-Photon Emission by Quantum Dot/Polymer Hybrid Particles. Macromol. Rapid Commun. 2013, 34, 1145-1150.

24. Ai, X.; Ma, Q.; Su, X. Nanosensor for dopamine and glutathione based on the quenching and recovery of the fluorescence of silica-coated quantum dots. Microchim. Acta 2013, 180, 269-277.

25. Maity, A.R.; Saha, A.; Roy, A.; Jana, N.R. Folic Acid Functionalized Nanoprobes for Fluorescence-, Dark-Field-, and Dual-Imaging-Based Selective Detection of Cancer Cells and Tissue. ChemPlusChem 2013, 78, 259-267.

26. Santra, S.; Liesenfeld, B.; Dutta, D.; Chatel, D.; Batich, C.D.; Tan, W.; Moudgil, B.M.; Mericle, R.A. Folate conjugated fluorescent silica nanoparticles for labeling neoplastic cells. J. Nanosci. Nanotechnol. 2005, 5, 899-904.

27. Gerard, V.A.; Maguire, C.M.; Bazou, D.; Gun'ko, Y.K. Folic acid modified gelatine coated quantum dots as potential reagents for in vitro cancer diagnostics. J. Nanobiotechnol. 2011, 9, 50, doi:10.1186/1477-3155-9-50.

28. Miotti, S.; Bagnoli, M.; Ottone, F.; Tomassetti, A.; Colnaghi, M.I.; Canevari, S. Simultaneous activity of two different mechanisms of folate transport in ovarian carcinoma cell lines. J. Cell. Biochem. 1997, 65, 479-491.

29. Miotti, S.; Facheris, P.; Tomassetti, A.; Bottero, F.; Bottini, C.; Ottone, F.; Colnaghi, M.I.; Bunni, M.A.; Priest, D.G.; Canevari, S. Growth of ovarian-carcinoma cell lines at physiological folate concentration: Effect on folate-binding protein expression in vitro and in vivo. Int. J. Cancer 1995, 63, 395-401.

30. Kirchner, C.; Liedl, T.; Kudera, S.; Pellegrino, T.; Javier, A.M.; Gaub, H.E.; Stoelzle, S.; Fertig, N.; Parak, W.J. Cytotoxicity of Colloidal CdSe and CdSe/ZnS Nanoparticles. Nano Lett. 2005, 5, 331-338.

31. Derfus, A.M.; Chan, W.C.W.; Bhatia, S.N. Probing the Cytotoxicity of Semiconductor Quantum Dots. Nano Lett. 2004, 4, 11-18.

32. Kailasa, S.K.; Wu, H.-F. One-pot synthesis of dopamine dithiocarbamate functionalized gold nanoparticles for quantitative analysis of small molecules and phosphopeptides in SALDI- and MALDI-MS. Analyst 2012, 137, 1629-1638. 
33. Mehta, V.N.; Mungara, A.K.; Kailasa, S.K. Dopamine dithiocarbamate functionalized silver nanoparticles as colorimetric sensors for the detection of cobalt ion. Anal. Methods 2013, 5, 1818-1822.

34. Calvert, P.; Yao, K.-S.; Hamilton, T.C.; O’Dwyer, P.J. Clinical studies of reversal of drug resistance based on glutathione. Chem. Biol. Interact. 1998, 111-112, 213-224.

35. Godwin, A.K.; Meister, A.; O’Dwyer, P.J.; Huang, C.S.; Hamilton, T.C.; Anderson, M.E. High resistance to cisplatin in human ovarian cancer cell lines is associated with marked increase of glutathione synthesis. Proc. Natl. Acad. Sci. USA 1992, 89, 3070-3074.

36. Coles, B.; Ketterer, B. The role of glutathione and glutathione transferases in chemical carcinogenesis. Crit. Rev. Biochem. Mol. Biol. 1990, 25, 47-70.

37. Malhotra, A.; Zhang, X.; Turkson, J.; Santra, S. Buffer-stable Chitosan-Polyglutamic Acid Hybrid Nanoparticles for Biomedical Applications. Macromol. Biosci. 2013, 13, 603-613.

38. Kumar, M.N.V.R. A review of chitin and chitosan applications. React. Funct. Polym. 2000, $46,1-27$.

39. Tallury, P.; Kar, S.; Bamrungsap, S.; Huang, Y.-F.; Tan, W.; Santra, S. Ultra-small water-dispersible fluorescent chitosan nanoparticles: Synthesis, characterization and specific targeting. Chem. Commun. 2009, 17, 2347-2349.

40. Silva, S.M.L.; Braga, C.R.C.; Fook, M.V.L.; Raposo, C.M.O.; Carvalho, L.H.; Canedo, E.L. Application of Infrared Spectroscopy to Analysis of Chitosan/Clay Nanocomposites. In Infrared Spectroscopy-Materials Science, Engineering and Technology; Theophanides, T., Ed.; InTech: Rijeka, Croatia; 2012.

41. Brugnerotto, J.; Lizardi, J.; Goycoolea, F.M.; Arguelles-Monal, W.; Desbrieres, J.; Rinaudo, M. An infrared investigation in relation with chitin and chitosan characterization. Polymer 2001, 42, 3569-3580.

42. Studer, K.; Decker, C.; Beck, E.; Schwalm, R.; Gruber, N. Redox and photoinitiated crosslinking polymerization. Prog. Org. Coat. 2005, 53, 126-133.

43. Wei, Q.; Zhang, F.; Li, J.; Li, B.; Zhao, C. Oxidant-induced dopamine polymerization for multifunctional coatings. Polym. Chem. 2010, 1, 1430-1433.

44. Tyagi, A.; Penzkofer, A. Fluorescence spectroscopic behaviour of folic acid. Chem. Phys. 2010, 367, 83-92.

45. Wang, J.; Sun, X.; Mao, W.; Sun, W.; Tang, J.; Sui, M.; Shen, Y.; Gu, Z. Tumor Redox Heterogeneity-Responsive Prodrug Nanocapsules for Cancer Chemotherapy. Adv. Mater. 2013, 25, 3670-3676.

46. Michelet, F.; Gueguen, R.; Leroy, P.; Wellman, M.; Nicolas, A.; Siest, G. Blood and plasma glutathione measured in healthy subjects by HPLC: Relation to sex, aging, biological variables, and life habits. Clin. Chem. 1995, 41, 1509-1517.

47. Clift, M.J.; Boyles, M.S.; Brown, D.M.; Stone, V. An investigation into the potential for different surface-coated quantum dots to cause oxidative stress and affect macrophage cell signalling in vitro. Nanotoxicology 2010, 4, 139-149.

48. Rosas-Hernandez, H.; Jimenez-Badillo, S.; Martinez-Cuevas, P.P.; Gracia-Espino, E.; Terrones, H.; Terrones, M.; Hussain, S.M.; Ali, S.F.; Gonzalez, C. Effects of 45-nm silver nanoparticles on coronary endothelial cells and isolated rat aortic rings. Toxicol. Lett. 2009, 191, 305-313. 
49. Kawata, K.; Osawa, M.; Okabe, S. In vitro Toxicity of Silver Nanoparticles at Noncytotoxic Doses to HepG2 Human Hepatoma Cells. Environ. Sci. Technol. 2009, 43, 6046-6051.

50. Montfort, R.L.M.V.; Congreve, M.; Tisi, D.; Carr, R.; Jhoti, H. Oxidation state of the active-site cysteine in protein tyrosine phosphatase 1B. Nature 2003, 423, 773-777.

51. Huang, H.-C.; Barua, S.; Sharma, G.; Dey, S.K.; Rege, K. Inorganic nanoparticles for cancer imaging and therapy. J. Control. Release 2011, 155, 344-357.

52. Zhang, Y.; Guo, L.; Roeske, R.W.; Antony, A.C.; Jayaram, H.N. Pteroyl- $\gamma$-glutamate-cysteine synthesis and its application in folate receptor-mediated cancer cell targeting using folate-tethered liposomes. Anal. Biochem. 2004, 332, 168-177.

53. Sears, D.; Osman, N.; Tate, B.; McKenzie, I.; Hogarth, P. Molecular cloning and expression of the mouse high affinity Fc receptor for IgG. J. Immunol. 1990, 144, 371-378.

54. Iversen, T.-G.; Skotland, T.; Sandvig, K. Endocytosis and intracellular transport of nanoparticles: Present knowledge and need for future studies. Nano Today 2011, 6, 176-185.

55. Fernando, L.P.; Kandel, P.K.; Yu, J.; McNeill, J.; Ackroyd, P.; Christensen, K.A. Mechanism of cellular uptake of highly fluorescent conjugated polymer nanoparticles. Biomacromolecules 2010 , 11, 2675-2682.

56. Clift, M.J.; Rothen-Rutishauser, B.; Brown, D.M.; Duffin, R.; Donaldson, K.; Proudfoot, L.; Guy, K.; Stone, V. The impact of different nanoparticle surface chemistry and size on uptake and toxicity in a murine macrophage cell line. Toxicol. Appl. Pharmacol. 2008, 232, 418-427.

57. Dong, S.; Cho, H.J.; Lee, Y.W.; Roman, M. Synthesis and Cellular Uptake of Folic Acid-Conjugated Cellulose Nanocrystals for Cancer Targeting. Biomacromolecules 2014, 15, 1560-1567.

58. Kortan, A.R.; Hull, R.; Opila, R.L.; Bawendi, M.G.; Steigerwald, M.L.; Carroll, P.J.; Brus, L.E. Nucleation and growth of cadmium selendie on zinc sulfide quantum crystallite seeds, and vice versa, in inverse micelle media. J. Am. Chem. Soc. 1990, 112, 1327-1332.

59. Basumallick, S.; Rajasekaran, P.; Tetard, L.; Santra, S. Hydrothermally derived water-dispersible mixed valence copper-chitosan nanocomposite as exceptionally potent antimicrobial agent. J. Nanopart. Res. 2014, 16, 1-11.

(C) 2015 by the authors; licensee MDPI, Basel, Switzerland. This article is an open access article distributed under the terms and conditions of the Creative Commons Attribution license (http://creativecommons.org/licenses/by/4.0/). 